\title{
Avaliação do trato gastrintestinal de equinos pela ultrassonografia transabdominal: nova abordagem
}

\section{Assessment of equine gastrointestinal tract using transabdominal ultrasonography: a new approach}

\author{
Carlos Henrique do Amaral1; Tilde Rodrigues Froes ${ }^{2 *}$
}

\begin{abstract}
Resumo
O diagnóstico ultrassonográfico transabdominal tem sido reportado como uma ferramenta diagnóstica importante na análise de equinos com síndrome cólica. O conhecimento detalhado da topografia das principais áreas que proporcionam janelas ultrassonográficas de valor diagnóstico para alterações do trato gastrintestinal deve ser bem estabelecido. O objetivo desse estudo foi descrever novas áreas de análise ultrassonográfica transabdominal da cavidade abdominal do equino, além de avaliar possíveis diferenças ultrassonográficas em animais de portes variáveis, inferindo sobre a aplicabilidade e as dificuldades da realização da técnica. Foram avaliados pela ultrassonografia transabdominal 20 cavalos, com transdutor convexo de frequência de 2,5 a 6,6 MHz em 11 áreas pré-estabelecidas. Os cavalos foram divididos em dois grupos de acordo com o porte. Compararam-se as estruturas passíveis de identificação em cada janela, suas características ultrassonográficas e as espessuras da parede nas diferentes porções do trato gastrintestinal. A divisão do abdome em janelas ultrassonográficas específicas não interferiu negativamente no tempo de realização do exame. Foram definidos padrões de normalidade para as janelas avaliadas, não existindo diferenças de dimensão e espessura de todas as porções avaliadas ultrassonograficamente em relação ao porte do animal. A divisão do abdome torna a avaliação topográfica do trato gastrintestinal mais precisa e padronizada, facilitando o diagnóstico das alterações de posicionamento e de distensão gastrintestinal oriundas das diferentes etiologias da síndrome cólica.

Palavras-chave: Cavalo, imagem, ultrassom, alças
\end{abstract}

\begin{abstract}
Transabdominal ultrasonography is reported to be an important diagnostic tool used in horses with abdominal pain. Detailed knowledge of the topography of the major areas that provide diagnostic values for each sonographic window with regard to the changes in the gastrointestinal tract should be well established. The aim of this study was to describe the new areas of the abdominal cavity of the horse examined using transabdominal ultrasonography and evaluate the possible ultrasound changes in animals of different sizes, thereby determining the applicability and difficulty in performing this technique. Twenty horses were examined using transabdominal ultrasonography at a convex transducer frequency of $2.5-6.6 \mathrm{MHz}$ at eleven established zones. The horses were divided into two groups based on their size. The potential for identification of the structures in each window was compared; the ultrasound characteristics and wall thickness in different parts of the gastrointestinal tract were described. Abdominal division in specific sonographic zones did not negatively impact the examination time, and the normal standards for the evaluated windows were defined. No sonographic differences were observed in the lumen size and thickness of all parts of the gastrointestinal tract evaluated according
\end{abstract}

1 Discente, Programa de Pós-graduação em Ciências Veterinárias, Universidade Federal do Paraná, UFPR, Curitiba, PR. E-mail: carlosamaralvet@gmail.com

2 Prof. do Programa de Pós-graduação em Ciências Veterinárias, UFPR, Curitiba, PR. E-mail: tilde@ufpr.br

Autor para correspondência 
to the size of the animal. Abdominal division enables a more precise and standardized topographic evaluation of the gastrointestinal tract, thereby enabling diagnosis of the changes and positioning that originate from different intestinal colic syndrome etiologies. This enables quick and accurate diagnosis.

Key words: Horse, imaging, ultrasound, bowel

\section{Introdução}

Mesmo com a evolução da medicina veterinária, a síndrome cólica equina continua sendo um desafio para o clínico-cirurgião de equinos. Aliado a isso, uma maior exigência do proprietário quanto a buscas e recursos apropriados para o seu correto diagnóstico e tratamento aumenta a cada dia. Os médicos veterinários especialistas na área enfrentam nos quadros de cólica a necessidade de uma decisão rápida e eficiente quanto à escolha do tratamento clínico ou cirúrgico (BECATI et al., 2011; REEVES et al., 1991).

Apesar das constantes evoluções, essa decisão baseia-se nos achados clínicos para que se possa chegar a um possível diagnóstico da causa da dor abdominal. Existem vários parâmetros que devem ser avaliados, tais como: grau de dor, distensão abdominal, frequência cardíaca, respiratória e características do pulso, coloração das membranas mucosas, tempo de preenchimento capilar, temperatura retal, motilidade gastrintestinal, refluxo gástrico, achados à palpação retal, hematócrito, concentração plasmática de proteínas totais, concentração plasmática de fibrinogênio; contagem de leucócitos, quantificação eletrolítica, análise de gases sanguíneos, quantificação das enzimas séricas, concentração de lactato plasmático, características do fluido peritoneal e também a ultrassonografia transabdominal (ALLEN; TYLER, 1990).

Tendo conhecimento da complexidade que envolve a síndrome cólica, a ultrassonografia apresenta propriedades interessantes para a avaliação do abdômen equino. É uma técnica não invasiva, dinâmica, que pode acompanhar a evolução do quadro clínico do animal. Permite a distinção de diferentes tecidos da cavidade por diferenças em sua ecogenicidade, ecotextura, tamanho e forma (FREEMAN, 2002a). Apesar dos possíveis artefatos devido à grande quantidade de gás no interior do trato gastrintestinal, a avaliação ultrassonográfica é possível em cavalos, assim como é feito em pequenos animais (PENNINCK; D’ANJOU, 2008).

A avaliação do trato gastrointestinal equino pela ultrassonografia é realizada por meio do conhecimento da topografia das estruturas, tamanho, características anatômicas, conteudos intraluminais e motilidade. A parede do intestino pode, por conseguinte, ser diferenciada de seu conteúdo, e os parâmetros tais como a espessura da parede e a frequência, amplitude e velocidade das contrações peristálticas podem ser avaliados pelo modo B, modo M e modo Doppler (FREEMAN, 2002a).

Diferentes autores descreveram as aplicações da ultrassonografia na cavidade abdominal para avaliação do trato gastrintestinal, definição da conduta terapêutica nos casos de cólica, ou até suspeitas de doença renal e hepática (ABUTARBUSH, 2006; BUSONI et al., 2011). Busoni et al. (2011) desenvolveram um protocolo de exame ultrassonográfico para pacientes com síndrome cólica, com o intuito de chegar a um diagnóstico ou ao menos auxiliar na escolha terapêutica. O protocolo é atualmente denominado FLASH - Fast Localized Abdominal Sonography in Horses.

Apesar dessas descrições, poucos trabalhos foram realizados para a padronização da técnica ultrassonográfica transabdominal em equinos saudáveis, bem como para validação de todas as janelas propostas para o exame e sua anatomia ultrassonográfica (BARTON, 2011). O objetivo desse estudo é descrever as características de normalidade para avaliação do trato gastrintestinal de equinos de diferentes portes, acrescentando novas áreas de avaliação ao que já foi proposto por 
Busoni et al. (2011). Inferir sobre a aplicabilidade da técnica em relação ao tempo de execução do exame e apontar as dificuldades da técnica.

\section{Materiais e Métodos}

O protocolo do presente estudo foi aprovado pelo Comitê de Ética para o Uso de Animais (CEAU/UFPR) registrado 029/2012. Foi realizada avaliação ultrassonográfica transabdominal em 20 equinos encaminhados ao Hospital Veterinário ou estabulados em haras das regiões próximas ao local do estudo. Os critérios de inclusão foram: cavalos de qualquer raça, porte ou idade sem sinais clínicos que indicassem afecção gastrintestinal.

Para realização do exame foi utilizado um aparelho de ultrassonografia portátil Esaote Mylab 30, equipado com um transdutor convexo 2,5 - 6,6 $\mathrm{MHz}$. O transdutor era multifrequencial sendo que durante o exame ajustava-se a melhor frequência, ganho, profundidade e zona de foco para otimizar a qualidade da imagem, isso de acordo com a estrutura que estava sendo avaliada e o porte do animal. A obtenção das imagens foi realizada por um único observador. Este com prática em clínica médica e cirúrgica equina tendo recebido treinamento técnico em ultrassonografia por 1 ano e prática de ultrassonografia da cavidade abdominal em equinos por 6 meses antes do início da coleta dos dados.

As avaliações ultrassonográficas foram realizadas dividindo o abdome do animal em áreas delimitadas chamadas aqui de janelas ultrassonográficas. As 11 janelas ultrassonográficas eram: 1) colocando-se o transdutor sob o terço médio do arco costal esquerdo entre o $8^{\circ}$ e $13^{\circ}$ espaço intercostal (EIC); 2) no flanco superior esquerdo caudal ao último arco costal; 3) no terço médio do arco costal esquerdo entre o $12^{\circ}$ e o $15^{\circ}$ EIC; 4) no flanco inferior esquerdo; 5) na região inguinal do lado esquerdo; 6) na região ventral do abdome e caudal à cartilagem xifoide; 7) no flanco superior direito iniciando-se a varredura caudal ao último arco costal e progredindo cranialmente até o $15^{\circ}$ EIC; 8) no flanco inferior direito; 9) na região inguinal direita; 10) no terço médio do arco costal do lado direito entre o $10^{\circ}$ e o $\left.12^{\circ} \mathrm{EIC} ; 11\right)$ no terço distal do arco costal do lado direito entre o $10^{\circ}$ e o $12^{\circ}$ EIC. Tais janelas estão demonstradas de forma esquemática na figura 1 .

Figura 1. Esquema da distribuição das áreas de pesquisa ultrassonográfica.
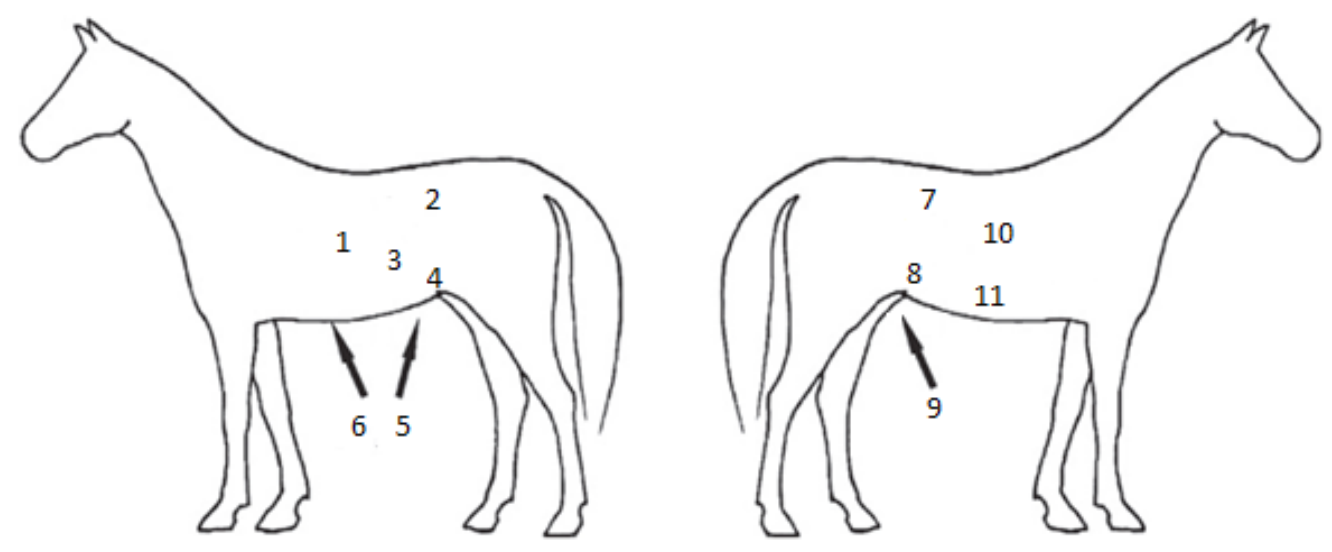

1-Terço médio do arco costal do lado esquerdo entre o $8^{\circ}$ e $13^{\circ}$ EIC. 2-Flanco superior esquerdo, caudal ao último arco costal. 3-Terço médio do arco costal esquerdo entre $12^{\circ}$ e $15^{\circ}$ EIC. 4-Flanco inferior esquerdo. 5-Região inguinal do lado esquerdo. 6-Região ventral do abdômen caudal à cartilagem xifóide do externo. 7-Flanco superior direito, iniciando caudal ao último arco costal progredindo cranialmente até o 15 EIC. 8-Flanco inferior direito. 9-Região inguinal do lado direito. 10-Terço médio do arco costal do lado direito, entre o $10^{\circ}$ e o $12^{\circ}$ EIC. 11 - Terço distal do arco costal do lado direito, entre o $10^{\circ}$ e $12^{\circ}$ EIC.

Fonte: Elaboração dos autores. 
Para tal, o pelo do animal foi molhado com álcool, sem uso de tricotomia. O estômago, rins, duodeno, ceco, cólon ventral esquerdo e direito, cólon dorsal esquerdo e direito foram examinados, bem como a pesquisa de líquido livre abdominal. As alças do intestino delgado foram avaliadas somente quando identificadas. Para cada área delimitada foi gravado ao menos um vídeo das imagens ultrassonográficas para posterior conferência e análise.

$\mathrm{O}$ peso dos animais foi obtido por meio de medição da circunferência torácica com o uso de fita métrica específica para tal função na espécie equina. O tempo de realização do exame foi cronometrado. Os exames foram realizados com os animais em tronco de contenção de equinos.

Foi realizada a descrição das estruturas visualizadas ultrassonograficamente em cada área previamente delimitada (figura 1). O estômago foi avaliado quanto à sua identificação, sua dimensão, espessura e estratificação de parede, sendo seu tamanho estimado de acordo com a contagem do número de espaços intercostais em que foi possível sua visualização (RABBA; BUSONI, 2009). O intestino delgado foi avaliado quanto à capacidade de ser identificado (sim ou não) e a região de visualização. Sua dimensão também foi contemplada por meio da mensuração do tamanho máximo da alça em corte transversal além da motilidade (normal, reduzida ou ausente). A motilidade do duodeno foi definida como "normal" quando apresentou mais de 3 contrações/minuto, "reduzida" quando apresentou menos que 3 contrações/minuto e "ausente" quando não houve contração (REEF, 1998). A motilidade das demais porções do intestino delgado foi definida como "normal" se tivesse contração contínua, "reduzida" se apresentassem menos que seis contrações/minuto e "ausente" se não houvesse contrações (REEF, 1998).

As porções do cólon ascendente visualizadas (cólon ventral direito, cólon ventral esquerdo, cólon dorsal esquerdo e cólon dorsal direito), foram avaliadas quanto à espessura da parede e motilidade em cada região. A motilidade foi considerada "normal" quando apresentou mais que duas contrações/minuto, reduzida quando apresentou menos de uma contração/minuto e "ausente" quando não apresentou contrações. A motilidade do ceco foi identificada como normal quando foi possível a visualização de uma descarga cecal durante o escaneamento (REEF, 1998).

O tipo de conteúdo das diferentes porções do trato gastrintestinal foi analisado e descrito. Para cada mensuração da espessura da parede das diferentes porções do trato gastrintestinal foram realizadas três medições sendo utilizada a média destas para a análise estatística. As medidas foram feitas pelos calipers eletrônicos do aparelho, colocados na serosa e na face interna da mucosa.

Para todos os exames buscou-se detectar a melhor área em que foi possível identificação do líquido peritoneal. Foi avaliada a possibilidade de visualização do rim esquerdo (classificada como sim ou não).

Os dados obtidos foram separados em dois grupo de animais: até $500 \mathrm{~kg}$ (Grupo I) e acima de $501 \mathrm{~kg}$ (Grupo II) em que os dados contínuos (espessura da parede, diâmetro de alça intestinal e número de espaços intercostais do estômago) foram comparados entre eles e entre grupos de peso, sendo utilizado para tal análise um modelo misto de variância (ANOVA). As diferenças foram consideradas significantes quando $\mathrm{p}<0,05$.

\section{Resultados}

Dos 20 cavalos incluídos no estudo, 11 animais eram machos e nove eram fêmeas. $\mathrm{O}$ peso médio dos animais foi 467,45 $\mathrm{kg}$ (mínimo de $345 \mathrm{~kg}$ e máximo de $610 \mathrm{~kg}$ ). Destes, 11 eram sem raça definida e os demais divididos entre as raças Puro Sangue Inglês (3), Quarto de Milha (3), Brasileiro de Hipismo (2) e Lusitano (1). Dez animais eram pertencentes ao grupo I (média de $547,3 \mathrm{~kg}$ ), e dez animais pertencentes ao grupo II (média de 387,6 
$\mathrm{kg})$, sendo estes pesos significativamente diferentes $\mathrm{p}<0,05$. O tempo médio de execução dos exames foi de 17:31 minutos, sendo o exame mais rápido executado em 14:00 minutos e o mais demorado em 24:00 minutos.

O estômago apresentou dimensão média de 4,7 espaços intercostais (EIC) com desvio padrão (s) de 0,71 EIC. Em todos os animais foi possível a visualização do estômago na janela ultrassonografica 1 (figura 1), iniciando-se no $8^{\circ} \mathrm{EIC}$ e indo até o $13^{\circ}$
EIC do lado esquerdo, ao nível da articulação do ombro. Em somente três animais o estômago foi visualizado em mais de 6 EIC. A espessura média da parede gástrica foi de $0,46 \pm 0,09 \mathrm{~cm}$. Não foi demonstrada diferença estatística $(p>0,05)$ entre $o$ grupo I e grupo II tanto para a espessura da parede gástrica, como para a sua dimensão (Tabelas 1 e 3). Quanto à estratificação das camadas da parede era possível diferenciar somente três camadas (mucosa, submucosa e muscular + serosa).

Tabela 1. Estruturas anatômicas com as áreas ultrassonográficas em que puderam ser encontradas e respectivos pontos de referência anatômica para a sua observação, em 20 equinos submetidos a exame ultrassonográfico transabdominal.

\begin{tabular}{|c|c|c|}
\hline Órgão/ estrutura & $\begin{array}{c}\text { Áreas } \\
\text { ultrassonográficas }\end{array}$ & Ponto de referência anatômica / observações \\
\hline Estômago & 1 & $\begin{array}{l}\text { Medial ao baço (região do hilo esplênico). Marcada } \\
\text { interface ecogênica do conteudo gasoso gástrico. }\end{array}$ \\
\hline Duodeno & 7 e 10 & $\begin{array}{c}\text { Ventral ao rim direito, entre este e o CDD (área 7) e/ } \\
\text { ou entre o fígado e CDD (área10). }\end{array}$ \\
\hline Intestino delgado & 4,5 e 9 & $\begin{array}{c}\text { Visualização de poucas alças de ID entre o baço e o } \\
\text { CVE (4) e entre as saculações do CVE e o CVD } \\
\text { (5 e 9). }\end{array}$ \\
\hline Cólon ventral direito & 8,9 e 11 & $\begin{array}{l}\text { Contato direto com a parede abdominal. Interface } \\
\text { ecogênica do conteúdo fecal/gasoso. }\end{array}$ \\
\hline Cólon ventral esquerdo & 3 a 6 & $\begin{array}{l}\text { Contato direto com a parede abdominal. Interface } \\
\text { ecogênica do conteúdo fecal/gasoso. }\end{array}$ \\
\hline Cólon dorsal direito & 7 e 10 & $\begin{array}{l}\text { Ventral ao rim direito e em contato com a parede } \\
\text { abdominal (7), medial ao fígado (10). }\end{array}$ \\
\hline Cólon dorsal esquerdo & 2 & Ventral ao rim direito. \\
\hline Ceco & 7 & $\begin{array}{l}\text { Contato com a parede abdominal, caudal ao rim } \\
\text { direito. Conteudo gasoso (artefato de reverberação). }\end{array}$ \\
\hline
\end{tabular}

Legenda: CDD, cólon dorsal direito; ID, Intestino delgado; CVE, cólon ventral esquerdo; CVD, cólon ventral direito.

Fonte: Elaboração dos autores.

O duodeno pôde ser identificado nas áreas 7 e/ou 10 (Figura 1) em 75\% (15) dos animais examinados (Tabela 2), tendo como conteúdo intraluminal fluido bastante ecogênico (Figura 2). Apesar da identificação dessa porção intestinal a mensuração da espessura da parede do duodeno foi de difícil execução. A medida média do maior diâmetro do duodeno em corte transversal foi de 3,64 $\pm 0,82$ cm (Tabelas 1 e 3). Não foi constatada diferença estatística $(p>0,05)$ entre os grupos quanto ao diâmetro do duodeno. O ponto de referência anatômico utilizado para se visualizar o duodeno foi a região entre o rim direito e o cólon dorsal direito (área 7) e/ou entre a porção direita do fígado e o cólon dorsal direito (área 10) (Figura 2). 
Figura 2. Imagem ultrassonográfica da área 10 (terço médio do arco costal do lado direito entre o $10^{\circ}$ e o $12^{\circ}$ EIC), transdutor convexo, frequência 2,5Mhz. Fígado em contato com a parede abdominal (seta branca grossa), cólon dorsal direito (sem saculações) representado pela identificação da parede e conteúdo fecal/gasoso hiperecóico (seta fina). Duodeno em corte transversal com conteúdo intraluminal ecogênico e homogêneo (asterisco).

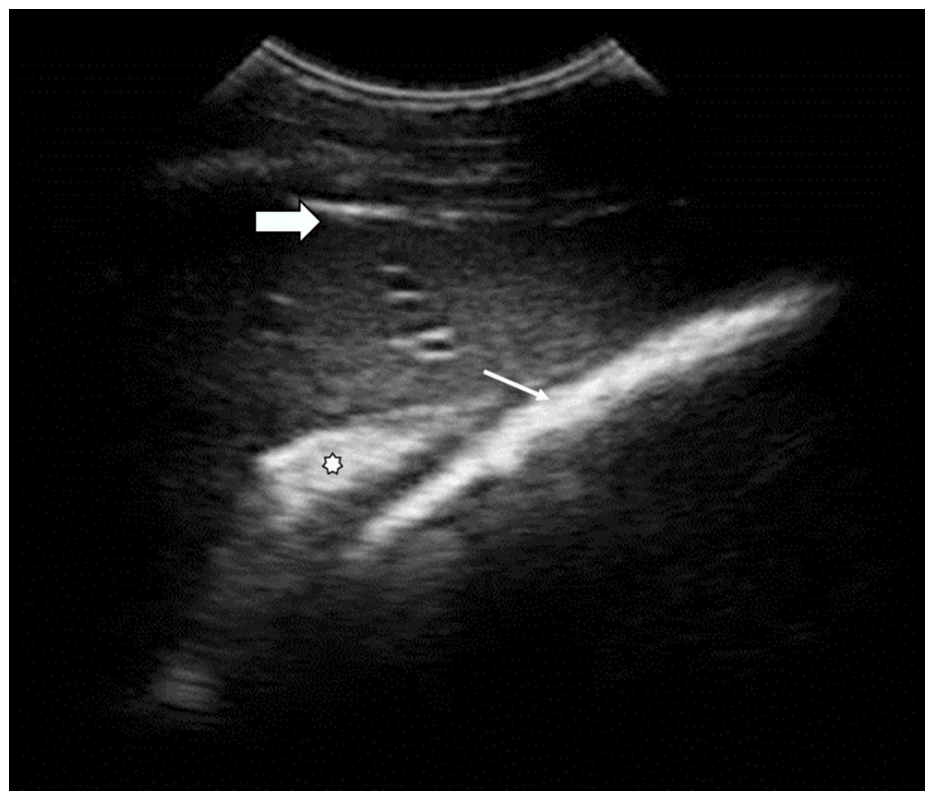

Fonte: Elaboração dos autores.

As alças de delgado (jejuno e íleo) puderam ser identificadas nas áreas ultrassonográficas 3, 4, $5,6,8,9$, sendo mais frequentemente visualizadas nas áreas 4, 5 e 9 (Tabela 2). As porções jejuno e íleo não puderam ser diferenciadas. A média do maior diâmetro das alças em corte transversal foi de 4,48 $\pm 0,73 \mathrm{~cm}$, com espessura de parede de $0,25 \pm 0,03 \mathrm{~cm}$ (Tabela 1 e 3 ). Não houve diferença estatística $(p>0,05)$ entre os grupos quanto ao diâmetro e espessura da parede do intestino delgado em nenhuma das regiões em que este foi observado. As alças apresentam conteúdo fluido ecogênico e homogêneo como característica normal (Figura 3).

O cólon ventral direito, cólon ventral esquerdo, cólon dorsal esquerdo e cólon dorsal direito puderam ser identificados durante o exame ultrassonográfico conforme demonstrado nas Tabelas 1 e 2. A distensão do cólon ventral direito e esquerdo foi avaliada subjetivamente pela observação das saculações características dessa porção (Tabela 1, Figura 3). Foi possível identificar os diferentes segmentos do cólon (maior) ascendente em todas as 11 áreas ultrassonográficas sendo que a espessura da parede não foi significativamente diferente entre as regiões $(p>0,05)$ apresentando média de 0,26 \pm $0,04 \mathrm{~cm}$ de espessura, exceto pela área 6 (flexura esternal),,região na qual a espessura da parede foi significativamente diferente das regiões 4, 5, 7, 9 e 11 com média de 0,23 $\pm 0,02 \mathrm{~cm}$. Não houve diferença significativa entre os grupos quanto à espessura da parede do cólon em nenhuma região avaliada. O conteúdo do cólon ventral apresentou característica bastante ecogênica devido a sua composição densa, que acaba por formar sombra acústica posterior o que possibilita apenas a visualização da parede em contato com a parede abdominal (Figura 3). O cólon dorsal apresenta conteúdo com maior quantidade de gás que, em alguns momentos, gera artefato de reverberação o que somado à ausência de saculações e à topografia permite a diferenciação destas porções do cólon (Tabela 3, Figura 2). 
Tabela 2. Frequência de visualização das estruturas em cada área ultrassonográfica em 20 equinos submetidos a exame ultrassonográfico transabdominal.

\section{Área Ultrassonográfica}

\section{Orgão Visualizado}

\section{Frequência de Visualização}

\begin{tabular}{|c|c|c|}
\hline $1 *$ & $\begin{array}{l}\text { Estômago } \\
\text { Cólon Ventral Esquerdo }\end{array}$ & $\begin{array}{l}100 \%(20) \\
80 \%(16)\end{array}$ \\
\hline 2 & $\begin{array}{l}\text { Cólon Dorsal Direito } \\
\text { Rim Esquerdo } \\
\text { Baço }\end{array}$ & $\begin{array}{l}100 \%(20) \\
95 \%(19) \\
90 \%(18)\end{array}$ \\
\hline 3 & $\begin{array}{l}\text { Baço } \\
\text { Cólon Ventral Direito } \\
\text { Jejuno/Íleo }\end{array}$ & $\begin{array}{c}100 \%(20) \\
100 \%(20) \\
20 \%(4)\end{array}$ \\
\hline 4 & $\begin{array}{l}\text { Cólon Ventral Direito } \\
\text { Baço } \\
\text { Jejuno/Íleo }\end{array}$ & $\begin{array}{c}100 \%(20) \\
95 \%(19) \\
95 \%(19)\end{array}$ \\
\hline 5 & $\begin{array}{l}\text { Cólon Ventral Direito } \\
\text { Baço } \\
\text { Jejuno/Íleo }\end{array}$ & $\begin{array}{l}100 \%(20) \\
75 \%(15) \\
70 \%(14)\end{array}$ \\
\hline 6 & $\begin{array}{l}\text { Cólon Ventral } \\
\text { Jejuno/Íleo }\end{array}$ & $\begin{array}{c}100 \%(20) \\
10 \%(2)\end{array}$ \\
\hline 7 & $\begin{array}{l}\text { Ceco } \\
\text { Rim Direito } \\
\text { Cólon Dorsal Direito } \\
\text { Duodeno }\end{array}$ & $\begin{array}{c}100 \%(20) \\
100 \%(20) \\
100 \%(20) \\
25 \%(5)\end{array}$ \\
\hline 8 & $\begin{array}{l}\text { Cólon Ventral Esquerdo } \\
\text { Jejuno/Íleo }\end{array}$ & $\begin{array}{c}100 \%(20) \\
5 \%(1)\end{array}$ \\
\hline 9 & $\begin{array}{l}\text { Cólon Ventral Direito } \\
\text { Jejuno/Íleo }\end{array}$ & $\begin{array}{l}100 \%(20) \\
75 \%(15)\end{array}$ \\
\hline $10 *$ & $\begin{array}{l}\text { Cólon Dorsal Direito } \\
\text { Fígado } \\
\text { Duodeno }\end{array}$ & $\begin{array}{l}100 \%(20) \\
85 \%(17) \\
75 \%(15)\end{array}$ \\
\hline 11 & Cólon Ventral Direito & $100 \%(20)$ \\
\hline
\end{tabular}

* Nesta região o pulmão pode obstruir parcialmente a visualização das estruturas abdominais causando artefato de reverberação. As diferentes estruturas podem ser identificadas em mais de uma área.

Fonte: Elaboração dos autores. 


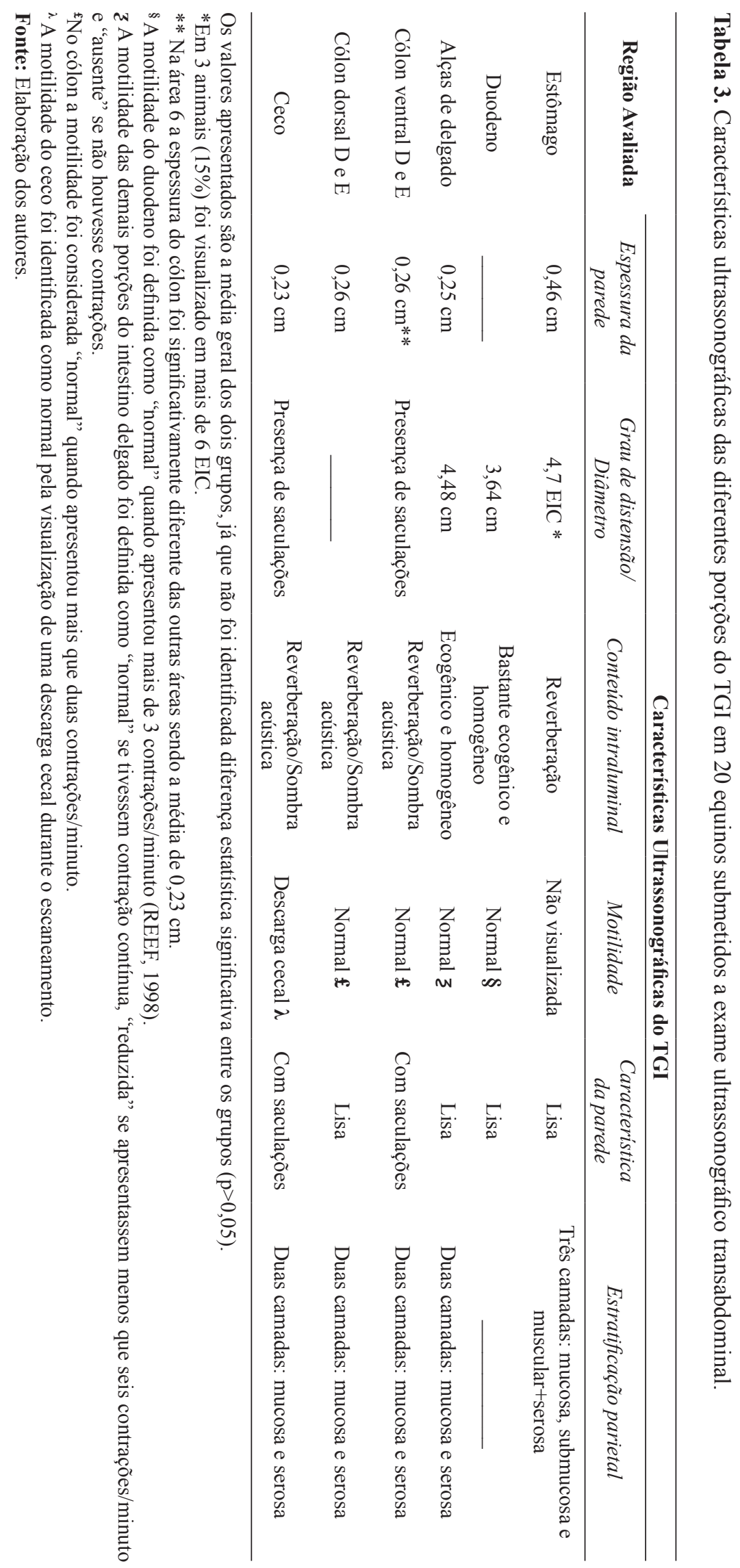


O ceco foi passível de identificação em todos os animais sendo visualizado sempre na janela ultrassonográfica 7 (Tabela 2), sendo que nesta região podemos observar apenas a base do orgão, apresentando relação estreita com o rim direito (cranial ao ceco), que também pôde ser identificado em todos os animais. A parede do ceco apresentou espessura média de 0,23 $\pm 0,03 \mathrm{~cm}$. Não houve diferença significativa entre os grupos quanto à espessura do ceco. A presença do gás, saculações e padrão de motilidade intensa durante a descarga cecal permite sua diferenciação do cólon dorsal direito, localizado cranial à base do ceco nesta mesma área (7) e do cólon ventral direito, localizado na região ventrolateral do abdome (área 8).

Todas as porções do trato gastrintestinal avaliadas apresentaram motilidade normal de acordo com padrão estabelecido para cada região como descrito nos métodos.

O rim esquerdo foi visualizado em 95\% (19) dos animais, sendo sempre identificado na área ultrassonográfica 2(Figura 1). Em animais saudáveis a visualização do baço, rim e cólon dorsal esquerdo estruturados dessa forma, da parede para a porção mais interna do abdome, foi a mais comum, sendo encontrada em 90\% dos animais avaliados; rim e cólon dorsal em 5\% dos animais e somente cólon dorsal direito em contato com a parede abdominal em $5 \%$ dos animais.

Foi possível a visualização do líquido peritoneal em $85 \%$ (17) dos animais. Sendo as áreas 4, 5, 6 e 9 (Figura 1) as regiões em que foi mais frequentemente encontrado. Em todos os animais e regiões em que foi identificado, o líquido apresentou-se anecoico. Em todos os animais em que foi possível a visualização do liquido peritoneal esse foi encontrado em pequena quantidade, sempre entre os haustros do cólon ventral (Figura 3).

Foi possível observar que em 2 animais com sobrepeso/obesos a formação das imagens ultrassonográficas foi dificultada.

Figura 3. Imagens ultrassonográficas obtidas com transdutor convexo, frequência 2,5Mhz da área 5 (região inguinal do lado esquerdo). A, visualização de cortes transversal e oblíquo de intestino delgado em contato com a parede abdominal, apresentando conteúdo ecogênico homogêneo (seta larga), dorsalmente presença linha ecogênica marca parede/conteúdo do cólon ventral direito (seta fina). B, visualização da borda do baço (asterisco), pequena quantidade de líquido peritoneal, entre os haustros do cólon ventral e alças de intestino delgado, com característica anecóica (seta larga).

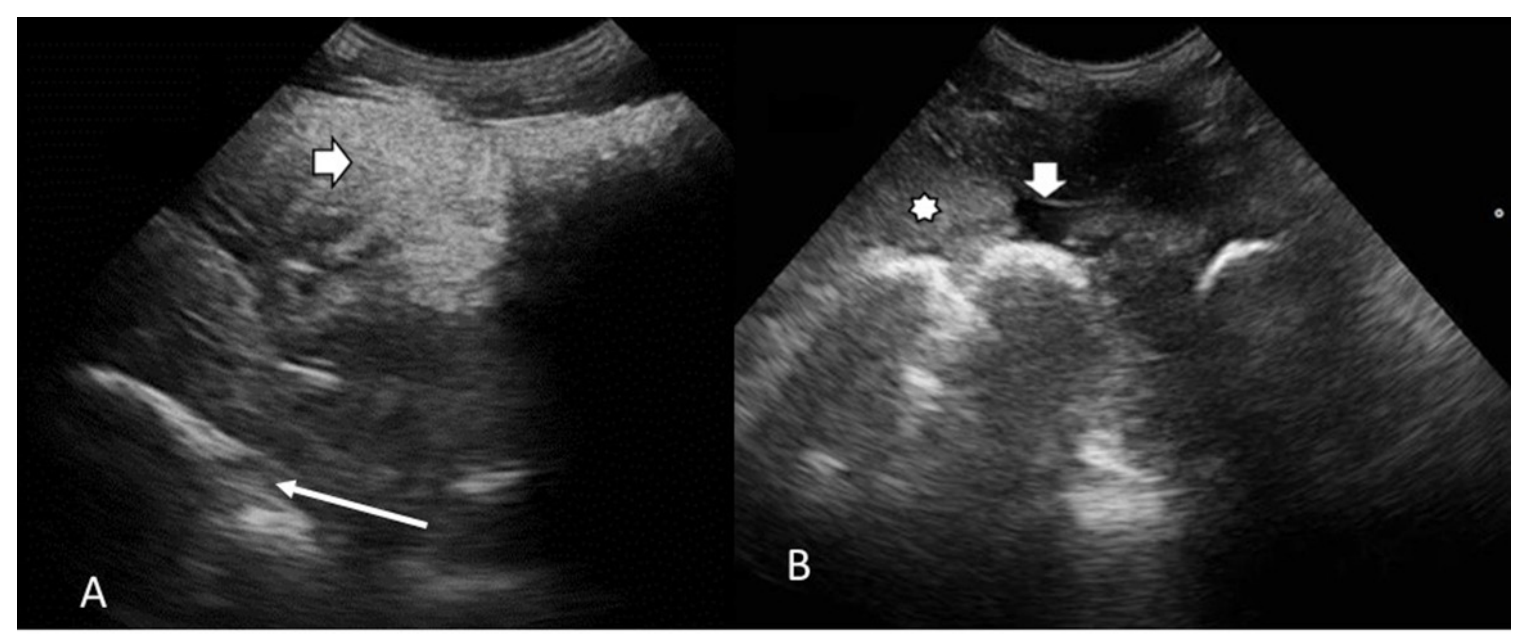

Fonte: Elaboração dos autores. 


\section{Discussão}

As 11 janelas ultrassonográficas estabelecidas nesse trabalho permitiram boa avaliação das diferentes estruturas da cavidade abdominal, e proporcionaram outros ângulos de análise para as diferentes porções do trato gastrintestinal. Tais fatos consolidam a aplicabilidade da ultrassonografia transabdominal como mais uma opção de método diagnóstico para análise do trato gastrintestinal. Os trabalhos anteriores publicados descreveram a metodologia em animais com cólica ou em pôneis saudáveis o que dificulta a descrição dos parâmetros de normalidade (BUSONI et al., 2011).

A metodologia proposta descreve novas janelas ultrassonográficas para melhor avaliação das diferentes porções do trato gastrintestinal. Tais áreas ultrassonográficas tiveram como objetivo ampliar a visualização de porções do trato gastrintestinal não bem identificadas em modelo anteriormente proposto (BUSONI et al., 2011), minimizando o efeito do tamanho da cavidade como limitação. Considera-se ainda que o conhecimento de novas áreas de pesquisa traz ao ultrassonografista mais informação das correlações topográficas dos órgãos abdominais permitindo a identificação do problema quando essas correlações estão alteradas.

Tendo como base para realização de três novas janelas ultrassonográficas utilizamos o esquema utilizado por Busoni et al. (2011), no qual se descrevem sete áreas de avaliação ultrassonográfica. Esses autores utilizam uma única janela na região ventral do abdome. Essa, em nosso estudo, foi dividida em três janelas (5, 6 e 9) (Figura 1). A divisão da porção ventral do abdome proporcionou mais janelas de identificação das alças intestinais de delgado.

No lado esquerdo do animal adicionamos as janelas ultrassonográficas 3 (terço médio do arco costal esquerdo entre o $12^{\circ}$ e o $15^{\circ}$ EIC) e 4 (flanco inferior) possibilitando uma avaliação mais ampla da porção lateral do cólon ventral direito, proximidades da flexura pélvica e visualização de alças de intestino delgado em topografia não habitual. A avaliação do lado direito foi realizada com quatro áreas (janelas) ultrassonográficas (7, 8,9 e 10) (Figura 1) ao invés das duas propostas por Busoni et al. (2011), proporcionando outros ângulos de avaliação das estruturas abdominais, principalmente do cólon dorsal direito e duodeno, cólon ventral direito, base cecal e rim direito. As janelas (inseridas ou subdivididas) permitiram, então, maior possibilidade de pesquisa ultrassonográfica, sendo que o conhecimento dessas janelas provavelmente auxiliarão na elucidação do diagnóstico nos casos de síndrome cólica.

A preocupação com a demora no exame, quando da introdução de novas áreas de acesso na metodologia, existe e deve ser considerada. Todavia, verificou-se que o exame não dispende muito tempo para ser executado (média de 17:31 minutos), não diferindo muito do que foi apresentado por Busoni et al. (2011) em que os exames foram executados entre 7 e 17 minutos, principalmente se realizado por um avaliador experiente. Os autores consideram que o maior número de informações obtidas por essas novas áreas de exame contribuirão para melhor a acurácia do exame sem comprometer ou retardar o atendimento de um caso de síndrome cólica. A ultrassonografia transabdominal é passível de ser realizada juntamente com outros procedimentos de admissão nos casos de síndrome cólica tais como sondagem nasogástrica, fluidoterapia e palpação retal, não sendo necessária a preparação prévia ou uma espera durante a execução do exame (BUSONI et al., 2011). Todavia essas áreas de análise ainda devem ser testadas em equinos com cólica.

A base para a observação do estômago foi o $10^{\circ}$ EIC do lado esquerdo, podendo o órgão ser visualizado caudal e cranial a este, sendo este apenas um ponto de referência para a avaliação do órgão. A principal limitação do exame da cavidade gástrica para essa espécie é a impossibilidade de analisar a região piloro-duodenal, em decorrência a distensão gasosa que provoca reverberação e da profundidade dessa estrutura, não sendo possível 
atingir tal porção mesmo com o transdutor de baixa frequência.

Corroborando com outras pesquisas prévias (FREEMAN, 2002b; BARTON, 2011; BUSONI et al., 2011), foi possível a identificação da curvatura maior do estômago em todos os animais (Tabela 1), tendo como ponto de referência anatômica o baço. A parede gástrica é bem delimitada e verifica-se estratificação regular, porém, diferentemente de cães e gatos, não foi possível a identificação das cinco camadas (PENNINCK; D’ANJOU, 2008) e sim de três (Tabela 2), isso em decorrência da menor frequência do transdutor (BARTON, 2011), o que é recomendado para atingir estruturas mais profundas. Ou seja, perde-se em detalhamento e, entretanto, aprimora-se a identificação do estômago. Isso é válido para todos os segmentos do trato gastrintestinal analisados nos equinos desse experimento. Apesar disso é possível analisar a espessura da parede gástrica e essa não foi influenciada pelo porte do animal (Tabela 1 e 3).

Pelo exame ultrassonográfico transabdominal foi possível mensurar a espessura da parede na maioria dos segmentos do trato gastrintestinal. A comparação desta análise nos diferentes segmentos, não apresentou diferença estatística entre os grupos I e II. Ou seja, a variação do peso dos animais não influenciou na espessura da parede do trato gastrintestinal dos animais avaliados. As medidas de espessura encontradas (Tabela 3) assemelhamse a estudos anteriores (REEF, 1998; SCHARNER et al., 2002). Dentre todos os segmentos avaliados notou-se que o ceco apresenta a espessura da parede mais fina, o que torna a delimitação mais difícil dessa porção ao exame ultrassonográfico.

O duodeno pode ser pesquisado em duas áreas distintas (7 e 10) (Tabela 1). Apesar de ser um órgão fixo pelo ligamento gastroduodenal que situa-se adjacente a ele, a sua identificação não foi possível em todos os animais dessa pesquisa (15/20). Provavelmente, a sua posição anatômica e a pouca distensão intraluminal (KIRBERGER; VAN DEN
BERG; GOTTSCHALK, 1995; BARTON, 2011) possam ter dificultado a sua visualização. A sua identificação se dá em pequenas porções e em cortes transversais (BARTON, 2011). Considerase ainda que o cólon dorsal direito, devido ao seu conteúdo gasoso/fecal intraluminal, venha a causar artefato de reverberação/sombreamento, prejudicando também a identificação do duodeno. A sua motilidade (peristaltismo) pode ser avaliada quando o mesmo é identificado, apresentando três contrações por minuto como padrão normal também nos animais desse estudo. Quando preenchido por conteúdo intraluminal seu diâmetro duodenal médio foi de 3,64 cm, não havendo diferença entre os portes dos equinos e sendo similar ao descrito por outros autores (BITHELL et al., 2010; BARTON, 2011; FREEMAN, 2002b). Assim como os órgãos de referência topográfica anatômica: fígado, cólon dorsal direito e rim (Tabela 1), que também foram similares aos reportados (BITHELL et al., 2010; BARTON, 2011; FREEMAN, 2002b).

A identificação do intestino delgado pode ser um desafio em equinos saudáveis, fato esse ressaltado por outro pesquisador (BARTON, 2011). Nesse experimento conseguiram-se boas janelas de identificação, focadas principalmente nas áreas do lado esquerdo ( 5 e 6) para essa análise. Porém, em outras porções do abdome, já no lado direito (área 9), as alças de delgado também puderam ser identificadas (Tabela 1). Devido às diferentes janelas para a análise do intestino delgado tal visualização foi possível em todos os animais. Salienta-se que, mesmo com as diferentes janelas supracitadas, o exame ultrassonográfico permite somente a visualização de uma amostra do intestino delgado e não a visualização de toda a sua extensão e comprimento no equino.

Para avaliadores inexperientes, inicialmente, pode ser difícil a diferenciação das alças de intestino delgado com os haustros do cólon ventral, uma vez que sempre quando visualizadas, as alças de delgado encontram-se em contato íntimo com esta porção, principalmente na região inguinal. 
Essa diferenciação pode ser feita visualizando com atenção o padrão de motilidade constante e pela modificação do posicionamento do transdutor, o que possibilita a visualização das alças em cortes transversais e longitudinais (MITCHELL et al., 2005; BARTON, 2011). Ressalta-se que pela ultrassonografia transabdominal não é possível a diferenciação dos segmentos de jejuno e íleo nos cavalos, dado também reportado por outros pesquisadores (MITCHELL et al., 2005; BARTON, 2011).

Para o intestino delgado a espessura da parede detectada foi semelhante à reportada na literatura (MITCHELL et al., 2005; BARTON, 2011), assim como a média de diâmetro luminal (Tabela 1 e 3 ). Qualquer distensão além dos valores reportados deve ser considerada um alerta ao ultrassonografista na pesquisa de processos obstrutivos (BUSONI et al., 2011).

Para as diferentes porções do intestino grosso, percebe-se que é possível, pela ultrassonografia, a análise. Porém, o artefato de reverberação e eventualmente sombreamento impedem a visualização das porções mais internas da parede (oposta à identificada próxima ao transdutor), e diferentes são as áreas a serem escaneadas (Tabela 1). Durante o exame, o ultrassonografista consegue distinguir o cólon dorsal e ventral, tanto do lado direito quanto do lado esquerdo, e essa diferenciação se dá pela característica de saculação do colón ventral (Tabela 3). Já o cólon dorsal apresenta subjetivamente uma maior quantidade de conteúdo gasoso, e pela posição do transdutor ao escanear o abdome, conseguimos assegurar essa diferenciação anatômica, principalmente em decorrência dos haustros do colón ventral.

Quanto à espessura da parede do cólon ventral esquerdo, na área 6, verificou-se que essa é significativamente menor $(0,23 \mathrm{~cm})$ em comparação às outras áreas 4, 5, 7, 9 e 11 (de 0,26cm). Porém, notou-se não haver diferença significativa da espessura entre os dois grupos. A média das espessuras da parede do intestino grosso detectadas nesse estudo assemelha-se a outras pesquisas anteriores (BITHELL et al., 2010; BARTON, 2011; FREEMAN, 2002b).

A identificação da base do ceco foi possível na área 7, e esse segmento apresenta características clássicas, que são sua posição caudal ao rim direito, a presença de saculações, presença gás com artefato de reverberação e o padrão de motilidade intenso durante a descarga cecal (Tabela 1 e 3). Para se visualizar a descarga cecal, o ultrassonografista deve ter calma e não movimentar o transdutor por alguns instantes, até que se obtenha esse efeito. $\mathrm{O}$ maior cuidado está na diferenciação entre o ceco e outros segmentos do cólon direito (ventral e dorsal), sendo que a característica ultrassonográfica supracitada da descarga cecal auxilia nessa diferenciação.

A avaliação da área 2 apresenta como padrão mais frequente a possibilidade de visualização do baço em contato com a parede abdominal, medial a este em direção ao interior da cavidade o rim e abaixo do rim o cólon dorsal esquerdo. Nestes casos, o rim pode ser de difícil identificação em alguns animais, principalmente em animais de porte maior $(>550 \mathrm{~kg})$, por se apresentar mais profundo na imagem ultrassonográfica. Vale ressaltar a descrição de outras possibilidades de visualização do cólon dorsal em animais saudáveis (cerca de $10 \%$ dos animais) sendo elas, a identificação apenas do baço e ventral a este o cólon dorsal, ou, então, a visualização somente do cólon em contato direto com a parede abdominal sem que isso signifique a presença de um encarceramento nefroesplênico, como descrito também por Busoni et al. (2011). Ou seja, a não identificação do rim esquerdo nem sempre deve ser considerada encarceramento.

Orim direitoneste estudo foi de fácil identificação, sendo visualizado em todos os animais na área 6 , normalmente, no $16^{\circ} \mathrm{EIC}$, sendo o rim direito uma boa referência para diferenciação do ceco (caudal) e do cólon dorsal direito (cranial), assim como, para visualização do duodeno, normalmente situado entre o rim e o cólon dorsal direito (Tabela 1). 
A pesquisa de líquido peritoneal é um ponto importante a ser considerado. Como relatado por Freeman (2002a), equinos saudáveis apresentam pouca quantidade de líquido peritoneal sendo, então, sua visualização esporádica, e, assim como nessa pesquisa, sendo identificado o líquido mais frequentemente nas porções mais ventrais e região inguinal (áreas 4, 5, 6 e 9), principalmente entre os haustros do cólon ventral durante o movimento peristáltico, sendo sempre de característica anecóica (BITHELL et al., 2010; FREEMAN, 2002a).

Apesar de ser um dado subjetivo, pondera-se sobre a dificuldade de se obterem boas imagens em pacientes com grande capa de gordura, principalmente na porção ventral do abdome, e tal fato é relatado em humanos (Pinto et al., 2010). Na tentativa de obter imagens adequadas, a sugestão é o ajuste do ganho (elevação) e na profundidade nos controles do equipamento. A grande quantidade de gordura absorve as ondas sonoras diminuindo a sua propagação e gerando perda na qualidade da imagem.

Como limitações a serem ponderadas, essa sistemática de avaliação com a introdução de novas áreas de análise ultrassongráfica precisa ser testada em animais com síndrome cólica, já que a pressa no exame, a dor do animal e o estresse da equipe de trabalho podem dificultar a avaliação. Devemos saber se o tempo de execução do exame nessas condições será o mesmo ou prejudicará a abordagem do paciente.

O maior conhecimento da anatomia ultrassonográfica transabdominal do trato gastrintestinal de equinos adultos e suas peculiaridades, e a abordagem sistemática da cavidade com a inclusão de novas áreas de análise, provavelmente, proporcionarão uma maior eficiência dessa técnica quando na abordagem de equinos com cólica. Porém, em concordância com outros autores, destaca-se que como outros procedimentos diagnósticos auxiliares, essa modalidade deve ser aplicada e interpretada respeitando os achados clínicos e os resultados de outros exames, servindo como uma excelente técnica complementar (BECATI et al., 2011; BUSONI et al., 2011).

\section{Conclusões}

Os padrões de normalidade ultrassonográfica do trato gastrintestinal foram estabelecidos não havendo variação da espessura da parede das alças ou diâmetro relacionados ao porte do animal. Novas áreas de análise foram definidas, aumentando-se a capacidade de observações das diferentes estruturas do trato gastrintestinal por outros ângulos de ensonação.

\section{Agradecimentos}

À Capes por proporcionar bolsa de estudos do metrado, e ao médico veterinário Daniel Capucho de Oliveira pelo auxílio na estatística.

\section{Referências}

ABUTARBUSH, S. M. Use of ultrasonography to diagnose large colon volvulus in horses. Journal of the American Veterinary Medical Association, Chicago, v. 228, n. 3, p. 409-413, 2006.

ALLEN, D.; TYLER, D. Pathophysiology of acute abdominal disease. In: The equine acute abdomen. Philadelphia: Lea \& Febiger White, 1990. p. 65-87.

BARTON, M. H. Understanding Abdominal ultrasonography in horses: which way is up? Compendium on Continuing Education for the Practicing Veterinarians, Yardley, v. 33, n. 9, p. 1-6, 2011.

BECATI, F.; PEPE, M.; GIALLETI, R.; CERCONE, M.; BAZZICA, C.; NANNARONE, S. Is there stastistical correlation between ultrasonographic findings and definitive diagnosis in horses with acute abdominal pain? Equine Veterinary Journal, Hobokken, v. 39, n. 8, p. 98105, 2011.

BITHELL, S.; HABERSHON-BUTCHER, J. L.; BOWEN, I. M.; HALLOWELL, G. D. Repeatability and reproducibility of transabdominal ultrasonographic intestinal wall thickness measurements in Thoroughbred horses. Veterinary Radiology \& Ultrasound, Raleigh, v. 51, n. 6, p. 647-651, 2010. 
BUSONI, V.; BUSSCHER, V. DE; LOPEZ, D.; VERWILGHEN, D.; CASSART, D. Evaluation of a protocol for fast localised abdominal sonography of horses (FLASH) admitted for colic. Veterinary Journal, London, v. 188, n. 1, p. 77-82, 2011.

FREEMAN, S. Ultrasonography of the equine abdomen: techniques and normal findings. In Practice, London, v. 24, n. 4, p. 204-211, 2002a.

Ultrasonography of the equine abdomen: findings in the colic patient. In Practice, London, v. 24, n. 5, p. 262-273, 2002 b.

KIRBERGER, R. M.; VAN DEN BERG, J. S.; GOTTSCHALK, R. D. Duodenal ultrasonography in the normal adult horse. Veterinary Radiology \& Ultrasound, Raleigh, v. 36, n. 1, p. 50-56, 1995.

MITCHELl, C. F.; MALONE, E. D.; SAGE, A. M.; NIKSICH, K. Evaluation of gastrointestinal activity patterns in healthy horses using B mode and Doppler ultrasonography. Canadian Veterinary Journal, v. 46, n. 2, p. 134-140, 2005.
PENNINCK, D.; D'ANJOU, M. Gastrointestinal tract. In: Atlas of small animal ultrasonography. Oxford: Blackwell Publishing, 2008. p. 281-318.

PINTO, N. V. P.; CHOJNIAK, R.; COHEN, P. M.; YU, L. S.; QUEIROZ-ANDRADE, M.; BITENCOURT, A. G. V. Comparison of three types of preparations for abdominal sonography. Journal of Clinical Ultrasound, Hoboken, v. 39, n. 4, p. 203-208, 2010.

RABBA, S.; BUSONI, V. Transabdominal ultrasonography in the adult horse. Journal Ippologia, Liege, v. 20, n. 2, p. 5-12, 2009.

REEF, V. B. Adult abdominal ultrasonography. In: . Equine diagnostic ultrasound. Philadelphia: W.B.

Saunders. 1998. p. 273-363.

REEVES, M. J.; CURTIS, C. R.; SALMAN, M. D.; STASHAK, T. S.; REIF, J. S. Multivariable prediction model for the need for surgery in horses with colic. American Journal of Veterinary Research, Chicago, v. 52, n. 11, p. 1903-1907, 1991.

SCHARNER, D.; RÖTTING, A.; GERLACH, K.; RASCH, K.; FREEMAN, D. V. Ultrasonography of the abdomen in the horse with colic. Clinical Techniques in Equine Practice, New York, v. 1, n. 3, p. 118-124, 2002. 